\title{
Worldwide Comprehensive Payment System: A Comparison
}

\author{
Shivali Dhaka \\ Assistant Professor \\ Amity University, Gurgaon, \\ India
}

\author{
Ashima Gambhir \\ Assistant Professor \\ Amity University, Gurgaon, \\ India
}

\author{
Saurabh Jaglan \\ Assistant Manager \\ Planning and Scheduling \\ DIMTS Ltd. Delhi, India
}

\begin{abstract}
A modern, efficient and reliable payments infrastructure is now an essential requirement for any country looking to promote growing financial markets and improve execution of monetary policy. To attract foreign investments a country must be capable of clearing and settling national as well as international transactions. For implementing such cost effective, comprehensive payment clearing and settlement systems that are java based (platform independent), many payment systems were designed by a company MONTRAN. One main challenge in design of these networks is their vulnerability to security attacks. In this paper, we study the different comprehensive payment systems and comparison between them and how these online payment systems prevent from cyber criminals to steal victim's personal online banking, webmail service and financial service account details.
\end{abstract}

Keywords:

GPS, ATS, MES, RTGS, SSO, CSM, ACH.

\section{INTRODUCTION}

Security has become a primary concern in order to provide protected payment systems in local as well as global environment. Payment system is an operational network governed by laws, rules and standards that links bank accounts for monetary exchange using bank deposits. It is established to accomplish the transfer of monetary value between mutually obliged parties. An efficient payment system reduces the cost of exchanging goods and services and helps in enhancing stability and development capacity of national economy. Earlier in the past, SpyEye and Zeus malware variants use webinject files to make fraud in banking accounts of victims and stole their personal online banking, webmail service and financial service account credentials. A Webinject file is a text file with lot of java script and HTML code. This file allows cyber frauds to target bank organization and inject specific code into victim's browsers so that they can use and modify the webpages the users access in real time. They consist of all the code required to make fool of victims into thinking the pop-ups are real. But now they have gone step further with the help of Automatic transfer systems, as it remained invisible inspite of webinject files that displayed pop-ups to steal information from their accounts. With Automatic transfer systems, several tasks are performed such as checking account balances and even conducting wire transfers using the victim's credentials without alerting them. Also with Automatic transfer systems scripts, the frauds modify the account balances and hide illegitimate transactions as not to reveal the traces of their presence to victims. This is a pure online banking fraud because cybercriminals no longer need user intervention to obtain money. Victim's systems are initially infected by Automatic transfer systems either by using phishing emails with links to phished pages or malware attachments or drive-by downloads from malicious or compromised legitimate sites. For the development of economy the payment system should be technically efficient. Modern payment systems are computerized and most money exists only as digital records on commercial bank accounts. This paper provides a brief overview of how payment technologies and the principles that underpin secure and reliable payments have evolved from sixteenth century up to the present day. It considered the key risk that arise and need to be mitigated in modern payment system. MONTRAN has developed payment and related systems that provide solutions for the international financial sector. Starting with commercial banks in New York and the United States, expanding into institutions in Western Europe, then Eastern Europe and the rest of the world, it has positioned its corporate strategy to accept the challenges of worldwide financial integration. Its use of modular components fully automates client payment services while significantly reducing the cost and risk associated with implementing complex payment applications and provides services locally as well as globally. It offers solution ranging from a simple client connection delivery payment to a system that provides a broad range of global services. The client payment services implementation consists of payment origination delivery options, relevant monitoring displays and broad-based reporting facilities. Payment services include the processing of a full range of settlement and clearing transactions including SEPA credit transfers and direct debits, foreign currency transactions including conversion, correspondent payments, remittances, checks, and foreign drafts. Instructions are enriched with Commission and Charges including special customer conditions, settlement instructions, economic codes, and accounting entries. Output messages are formatted and transmitted and acknowledgements are sent. As the international banking community responds to market requirements, Montran's role in meeting these demands expands commensurately. They offer a complete line of integrated payment solutions and related products for the financial services industry, including: Global Payment System (GPS), Automated Transfer System (ATS), Real Time Gross Settlement System (RTGS), and Message Gateway (MES). 


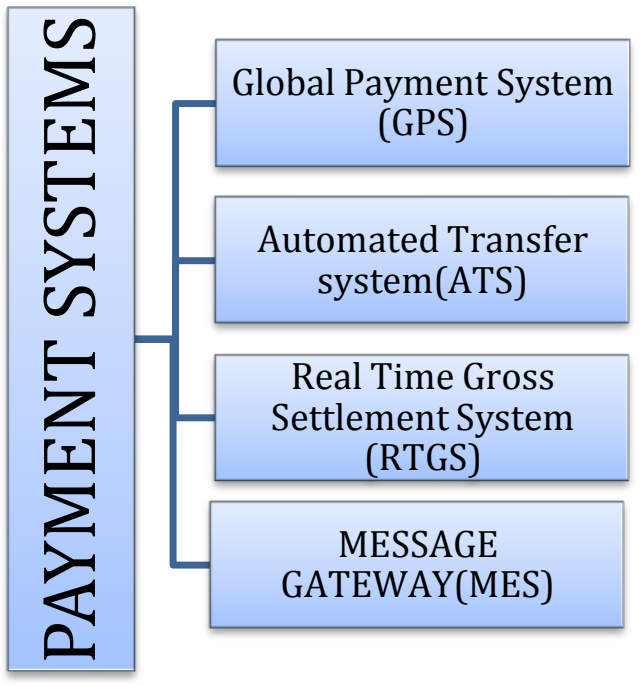

The paper is divided as follows: Section 2 Basic information on the methods of payments systems used by MONTRAN with their specific features. Section 3 presents the comparison between them by using various parameters. Section 4 concludes the paper.

\section{PAYMENT METHODS}

Throughout history there have been many different manifestations of money, both physical and electronic. In order for money to function as a medium of exchange there needs to be a system to enable transfer of value that is a payment system. A modern efficient and reliable payments infrastructure is now an essential requirement for any country looking to promote growing financial markets and improve execution of monetary policy. A country must be capable of clearing and settling a wide range of transactions according to international standards to be successful in attracting in foreign investment. MONTRAN has developed different payment methods, which make transactions more secure and efficient that are as follows:

\subsection{GPS}

This is an online payment system for Automatic Processing of all payments both foreign and domestic. It has certified interfaces to clearing and settlement systems all over the world. GPS consolidates all payment infrastructures into a payment hub that supports multiple banks and branches, in multiple countries, using multiple currencies, in multiple languages. GPS is a truly global solution and is running on all popular platforms and relational databases. It delivers outstanding and scalability and reliability. GPS is an interpretative payments hub that enables global banks to compete more effectively and got it success by automation, standardization and straight through processing. It has a highest level of protection and confidential transaction. Data access security is provided both digital signature and public key encryption technology. Following are the features of GPS.

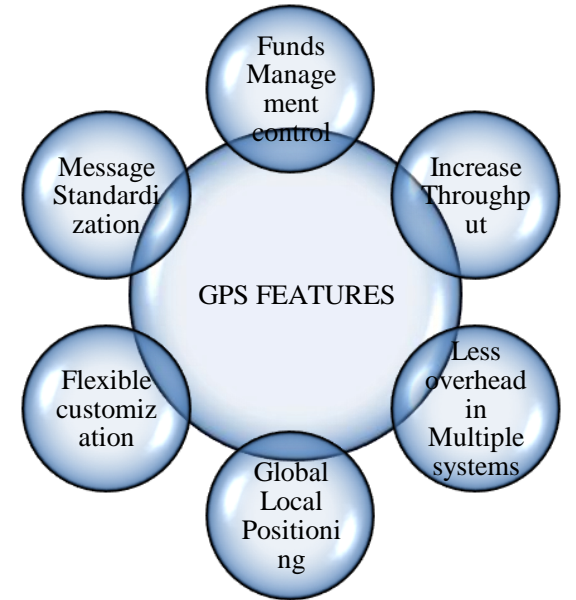

Fig 2.1 Features Of GPS

\subsection{RTGS}

RTGS is the standard for large-value interbank funds transfer to improve efficiency and reduce risk. Real-time gross settlement systems (RTGS) are funds transfer systems where transfer of money or securities takes place from one bank to another on a "real-time" as it does not require any waiting period and on "gross" basis as transaction is settled on one to one basis without bunching or netting with any other transaction.

It is designed to meet the standard required by central banks. RTGS handles very high volumes of large value domestic payments and provide liquidity management system. RTGS use Java Enterprise Architecture and components combine with RDBMS and PKI based security. RTGS system offers a complete Anti Money Laundering (AML) system for the identification and blocking of transactions involving parties found on OFAC - Office of Foreign Asset Control, Global Watch Lists, LAC - Local Asset Control, European and other country AML Lists. Data access security in RTGS is again provided through both digital signature and public key encryption technology. Following are the features of RTGS:

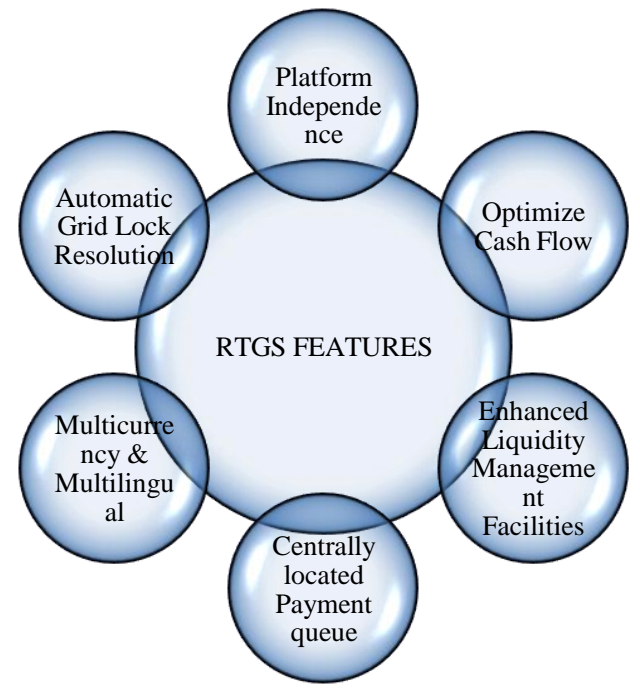

Fig 2.2 Features Of RTGS 


\subsection{MES:}

In response to the growing need by the customers for access to Multiple Clearing and Settlement Mechanisms (CSM), the message gateway was developed. It helps in exchanging of message and sharing of resources that is terminal and security features such as Single sign on (SSO) notification, alerts and online help documentations between multiple users. It handles all routing of messages externally and internally between Montran systems and other Bank component systems. The Message Gateway handles all the routing, delivery, monitoring, management control, investigation and reconciliation of the messages including ACK/NAK processing. It connects to multiple GPS applications representing different countries regions or a centralized payment hub, each capable of operating independently and includes configuration parameters for localization requirements.

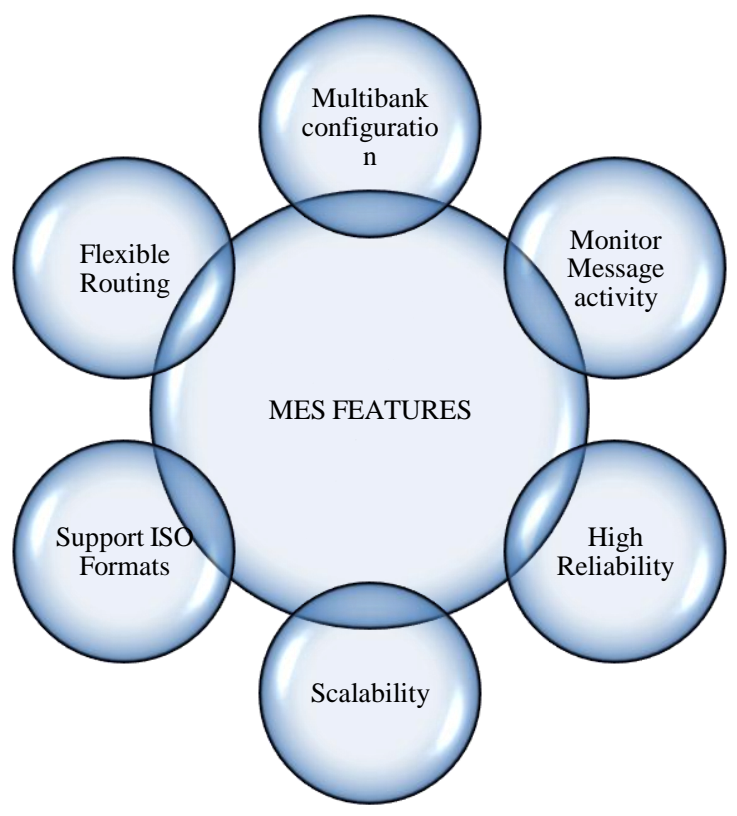

Fig 2.3 Features Of MES

\subsection{ATS:}

The ATS is an integrated interbank funds transfer system, which combines features of RTGS and automated clearing house (ACH). The RTGS component of the ATS enables high value and time critical transactions to be settled in real time while the $\mathrm{ACH}$ component provides clearing and netting facilities for a range of low value electronic payments. ATS is also an electronic clearing system that enables files of low-value payment instructions, including truncated cheques together with their scanned images, to be exchanged among financial institutions. The modern architecture and flexible tools of the ATS solution makes it easier to optimize the cash flows, to enable flexible STP and to enhance liquidity management facilities necessary for the oversight and execution of monetary policy.

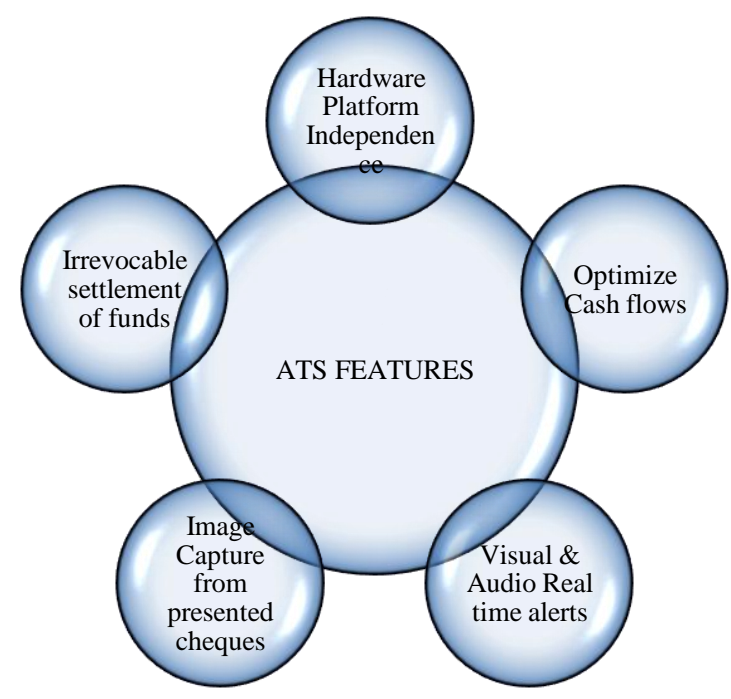

Fig 2.4 Features Of ATS

\section{COMPARISON OF PAYMENT SYSTEMS}

MONTRAN payment system consists of different automatic transfer systems. Each has some different and unique feature that differentiates them from others as shown in Table 3.1. All the payment systems are best in controlling funds management. While GPS and MES deal with global transactions, ATS and RTGS deal in transferring of funds locally. But in case of security feature, all of them use digital signature with public key encryption technology, providing the best protection mechanism from cyber frauds that make use of these automatic transfer systems to gather all banking and transaction information of victims. Both ATS and RTGS have centrally located queuing of payments making them more technically efficient in local loops. Except MES, all are having customizable menus by way of user profile functions and even deal in multiple languages and currency to make customers feel comfortable while availing the services. MES is made cost effective by allowing sharing of resources between different branches. . Notification to customers in form of visual and audio alerts is also provided by ATS.

\begin{tabular}{|l|c|c|c|c|}
\hline \multicolumn{1}{|c|}{ KEY } & GPS & ATS & RTGS & MES \\
\hline $\begin{array}{l}\text { Funds } \\
\text { Management } \\
\text { control }\end{array}$ & YES & YES & YES & YES \\
\hline $\begin{array}{l}\text { Global } \\
\text { /Local } \\
\text { Positioning }\end{array}$ & GLOBAL & LOCAL & LOCAL & GLOBAL \\
\hline $\begin{array}{l}\text { Digital } \\
\text { signature \& } \\
\text { public key } \\
\text { encryption } \\
\text { technology }\end{array}$ & YES & YES & YES & YES \\
\hline $\begin{array}{l}\text { Central } \\
\text { payment }\end{array}$ & NO & YES & YES & NO \\
\hline
\end{tabular}




\begin{tabular}{|l|c|c|c|c|}
\hline queue & & & & \\
\hline Customizable & YES & YES & YES & NO \\
\hline $\begin{array}{l}\text { Multiple } \\
\text { currency \& } \\
\text { languages }\end{array}$ & YES & YES & YES & NO \\
\hline $\begin{array}{l}\text { Anti-Money } \\
\text { laundary } \\
\text { system }\end{array}$ & YES & NO & YES & NO \\
\hline $\begin{array}{l}\text { Multiple } \\
\text { clearing } \\
\text { system }\end{array}$ & NO & NO & NO & YES \\
\hline $\begin{array}{l}\text { Shared } \\
\text { Resources }\end{array}$ & NO & NO & NO & YES \\
\hline $\begin{array}{l}\text { Visual } \\
\text { audio real } \\
\text { alerts }\end{array}$ & YES & NO & NO & \\
\hline
\end{tabular}

Table 3.1: Comparison with GPS, ATS, RTGS and MES

As shown in the graph below in Fig 3.1, ATS is better than RTGS and others in efficiency and throughput. All of the payment systems provide the same security level except the MES, which provide investigation and monitoring of all activities of message, and also has increased optimized cash flow.

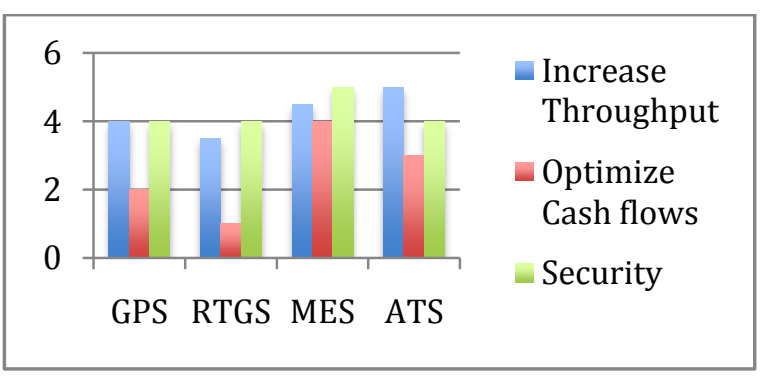

Fig 3.1: Comparison between payment systems in terms of efficiency

\section{CONCLUSION}

Comprehensive payment systems by MONTRAN have been reviewed in this paper. These payment techniques are used to provide security so that customers get able to do secure transactions in an effectively manner. Main advantages of these payment systems are its use of strong two-factor authentication with combination of digital signature and public key encrypted technology followed by four or even six-eye approval policy. Also the ability to investigate message relevant status at any point helps in monitoring all message activity. With the help of Anti Money Laundering (AML) system, it has become easy to identify and block illegal transactions. So, in future, because of advanced security features they can prevent us from cyber frauds by not allowing automatic transfer system to become their victim.

\section{REFERENCES}

[1] Dhirendra Pandey, Dr. A. Rastogi, "A Critical Research on threats and security technology related to Payment System on E-commerce Network ", International Journal Of Computer Applications (0975 - 8887) Volume 8- No.3, October 2010.

[2] Ajeet Singh, Karan Singh, Shahzad, "A Review: Secure Payment System for Electronic Transaction "International Journal of Advanced Research in Computer Science and Software Engineering , Volume 2, Issue 3, March 2012 ISSN: 2277 128X.

[3] K.Rama Kalyani, D.Uma Devi, "Fraud Detection of Credit Card Payment System by Genetic Algorithm", International Journal of Scientific \& Engineering Research Volume 3, Issue 7, July-2012 ISSN 22295518.

[4] S.Benson Edwin Raj, A. Annie Portia, "Analysis on Credit Card Fraud Detection Methods", IEEE International Conference on Computer, Communication and Electrical Technology, IEEE March 2011.

[5] Atul Raman, "Financial Inclusion and Growth of Indian Banking System", IOSR Journal of Business and Management (IOSRJBM) ISSN: 2278-487X Volume 1, Issue 3 (May-June 2012), PP 25-29.

[6] Akudo C. Anyanwu, Absalom E. Ezugwu, Sale E. Abdullahi, "Electronic Payment System (EPS): Facilitating the Development and Adoption in Nigeria", IJCSI International Journal of Computer Science Issues, Vol. 9, Issue 2, No 1, March 2012 ISSN (Online): 1694-0814.

[7] Ailya Izhar, Aihab Khan, Malik Sikandar Hayat Khiyal," Designing And Implementation Of Electronic Payment Gateway For Developing Countries", Journal of Theoretical and Applied Information Technology, ISSN-192-8645.

[8] Yang Jing, "On-line Payment and Security of Ecommerce" Proceedings of the 2009 International Symposium on Web Information Systems and Applications (WISA'09) Nanchang, P. R. China, May 22-24, 2009, pp. 046-050. 